\title{
Introducing systemic risk management to engineering consultation industry: A case study
}

\author{
Reem S. AbdAlla, andFouad Khalaf ${ }^{2}$ \\ ${ }^{1}$ Lecturer, Faculty of Engineering, Cairo University (CUFE) \\ ${ }^{2}$ Professor of Petroleum Engineering, CUFE, Coordinator of REM
}

\begin{abstract}
Engineering consultation industry plays a central role in developing countries. This industry approaches risk management by using a set of practices related to risk which the industrial project are exposed. However, this limited angle does not satisfy the complexity and nature of real life risks. This paper introduces a systemic approach, supposedly to improve handling project risks through better identifying and managing project risks in the engineering consultancy in Egypt. The proposed model supports the holistic concepts of system definition and hazard identification. The model has been applied in one of Egyptian expert houses as a pilot project. Outcomes of this research will allow the engineering consultants to develop/improve performance if the proposed concepts of systemic risk management are applied.
\end{abstract}

Keywords: Systemic Risk Management, Engineering Consultation Industry, Preliminary Risk Assessment.

\section{Introduction}

Engineering consultation industry, is an important service- based industry, provides the other trades with practical solutions based on theoretical frame of engineering sciences [1]. In providing services, the industry is exposed to different levels of risk. However, few academic publications have addressed these threats [2]. The published researches focused on industry problems and difficulties, highlighted the challenges of the engineering service industry based on a macro- environment model regardless of the economic conditions of the country [3]. Risk exists as inevitable part in the consultation services. It is imperative therefore to consider risk control in a way that brings business undesired events down to acceptable or tolerable levels.

This paper presents an approach integrating traditional risk management and systems thinking, called herein Systemic Risk Management, in order to control risk which in turn should improve overall performance.

Nowadays, there is a considerable interest to the risk management, particularly in the construction industry due to the involvement of several stakeholders in the projects [4]. Project risks are perceived differently from the two sides of the project: the customer, who represent the decision making side, and the contractor who thinks of the impact of risks on project costs [5]. Besides these two ends of the project, customer and contractor, there is a third member who has a significant linking role between the project parties. This member is the consultant engineer.

Handling risks in engineering services field was initially associated with managing the risks of projects or risks involved in operations of engineering organization. Several publications on risk management related to engineering disciplines are focused on either the technical issues of the discipline or on the method(s) of managing the risks in the projects [6]. This approach is based on a set of pre-defined user requirements and/or technical specification. However, such mode of thinking is not appropriate for the complexity raised by variables that exist in the practical life, where supporting sub-systems are highly interconnected to the performance of the whole system. This approach does involve the trans-disciplinary nature of risk in the analysis, which crosses both boundaries of project and operation. Goral, during his study of the risks associated with the pre- design phase, recommended introducing all project parties to the process of identifying risk in early stage of the project, in addition to developing common understanding for the risk in the entire system [7]. This is in line with the requirements of ISO31000.

One of the most common methods to handle the complexity of the system is the tree-form hierarchal structure, which depends on decomposing the system into intermediate subsystems, then dividing each intermediate subsystem into further smaller sub systems for better management [6]. This approach has been followed in developing the principal idea of systemic approach of managing risks in this research.

\section{${ }^{1}$ Reem S. AbdAlla: rimsaid72@gmail.com \\ ${ }^{2}$ Fouad Khalaf: fouad.khalafm@gmail.com}




\section{Engineering consultation service in Egypt}

Engineering consultation service has played an important role in Egypt, particularly in the recent decade. The International Federation of Consulting Engineers (FIDIC) defines the five main services in which the consulting engineers has a role in the project,carrying out the investigation and reports, performing detailed design and preparation of contract documents, arranging a construction contract, supervising the contractors during construction, and approving/accepting performed work followed by carrying out the commissioning and issuing the final account [8]. All these services can be undertaken either partially or entirely, i.e. engineering consultation firms can perform some of these services or being in charge in all of them according to customer requirements.

The Egyptian Syndicate of Engineers defines the consulting engineer: "The consultant engineer is considered the topclass of engineering groups, where he fully practices his profession in one of the areas mentioned in the syndicate regulation. Identified consulting fields in the regulation are civil, electrical mechanical, architectural, chemical, textile and mining engineering [9]. The Egyptian Syndicate of Engineers categorize the engineering consultancy firms according to the size and type of work provided as single specialty, multiple specialty and expert house which is the highest level of engineering firm in Egypt.

\section{Systemic risk management}

Risk management process becomes more complex due to the different ways of perceiving risk between different parts of the project or industries. Even in the same industry, there is a variation between the understandings of the risk nature and characteristics between stakeholders. Recent researches consider risk management as systematic iterative process, where identifying the risk events, evaluating the probability of their occurrence and the severity of their consequences, then applying risk control measures and finally monitoring the risk management plan to provide any required updates accordingly.

In this research we adopt the holistic thinking during employing risk management process. This requires clear understanding for the components of the system under study, as well as the relations between these components before going through the risk identification process. This step is important for creating common understanding of threats confronting the whole organization.Then contribution of the paper is that it applies the traditional five-step approach to the specific case of an Egyptian provider of consulting services, mentioned in Section 5 titled Methodology [10]:

1) System definition; to study the context of the system which shall be studied.

2) Hazards identification, to identify potential hazards which may confront the system.

3) Risk estimation; to estimate probability of occurrence and severity of risk consequences.

4) Risk evaluation; to determine the rank of each risk.

5) Risk control, to identify the appropriate methods to control the high risks.

But, Systems Thinking techniques play a prominent to fulfil the adage "Think globally, act locally" and now on the word systemic shall replace the systematic to signal that prominence.

The probability and severity of risk is gauged by four point scale to evaluate the risk based on the product of these two factors. Finally, an evaluation for all risk events in the system is implemented to identify the acceptable and non-acceptable events. Fig 1, illustrates the proposed process of risk management. 


\section{Engineering consultation work processes}

Engineering consultation -one of the service based industries - has no final tangible/hard form output, and cannot be packed. Therefore, there is no standard form for producing the engineering service. The output can be a final/soft report, drawing or a study. The input to this system comes mainly from the problems confronting customers represented in customer requirements and the technical specifications and legal regulations governing the project. The internal work process differs between firms and sometime, in the same firm, depending on customer requirements. However, the work processes of engineering consultation can be expressed in four main work processes [11]; business development which is crucial in obtaining work opportunities, project management processes because this type of business is project based one, core work processes which are determined based on the required service, in addition to supportive processes where all works has indirect input to the provided services. All the system processes are interacting with each other, where any deficiency in one of these sub-systems influences the overall performance.

\section{Research methodology}

This research applies systemic risk management to engineering consultancy industry. A case study from Egypt is selected for this purpose. The proposed methodology has involved:

1) A wide ranging literature review to understand the application of risk management particularly in engineering consultancy service.

2) Investigating the researches of engineering consultancy industry in Egypt as well as the local work environment and circumstances.

3) Introducing a systemic approach for risk management in engineering consulting firms. The approach is validated to the congenital risk management steps and ISO31000 requirements.

5) Applying the systemic risk management model on a pilot project; an Egyptian consulting expert house and analysing the results.

\section{Preliminary research outcomes}

In this research, a French version of the preliminary risk assessment, APR is used for identifying and evaluating risks in an Egyptian engineering consulting firm [12]. The model was verified with reference to the traditional five steps of risk management, and the requirements of ISO standards. The applied model is semi-quantitative, where a functional analysis for the system components is performed first, and then brainstorming technique is used to identify the potential internal and external hazards which may threaten the system.

The following step, estimating the undesired events generated from the interaction between the potential hazards and the system components. A comprehensive study for the last five years projects, in the case company is implemented to estimate values for risk factors; probability of occurrence for each risk scenario and the impact of its severity.

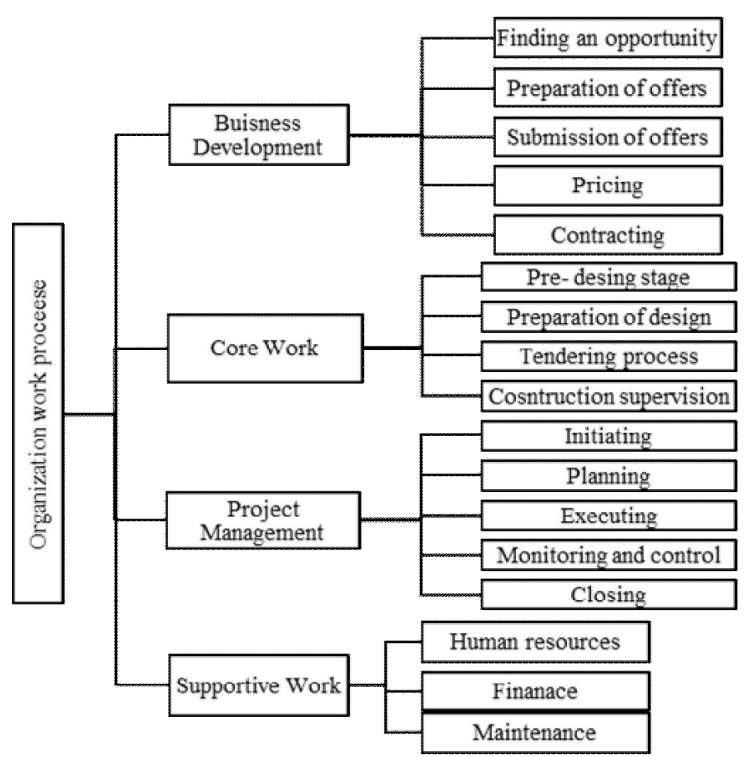

\subsection{Functional analysis of work processes}

Fig. 2: Functional Analysis of the Case Company

The first step in risk management system is to have a wide study for the system of the case company, particularly from the work processes perspective, which represents a crucial factor in the sustainability of the business. A systemic functional analysis is performed, considering entire work process including all elements which have direct or indirect liaison with the company's projects. Thus the analysis considered the synergy between the whole components of the system, It covers the whole project life cycle, starting from looking for a work opportunity, pas lsing by the core technical processes which used to find a solution for the client and the management processes needed to successfully 
finalize the project, and ending with the supportive work processes which has indirect influence of the successful completion of company's project. The objective of the functional analysis of the work processes is to understand the work in the complex system by breakdown the work performed in the pilot case into small parts can be managed easier. The results of functional analysis for work process in the case company are illustrated by the tree, Fig. 2.

\subsection{Hazards breakdown structure}

This research followed a hazard breakdown structure model to study the external and internal hazards confront the operation system of the case study. Several sessions is carried out with managers, employees and supportive staff to identify the hazards in their working process. The output of group sessions is validated with the sources of risks studied previously in literature review and with expert's judgment. Porter model is utilized, as an effective tool for analysing service based industries, when discussing the sources of external hazards in terms of five forces; new entrants, substitutes, suppliers, and customer. Another important force is added, which is the stakeholders [13]. Results of hazard identification step are presented in Table 1.

Table 1: Hazard Identification

\begin{tabular}{|l|l|}
\hline Hazard Category & Examples for the hazards \\
\hline \multicolumn{2}{|l|}{ External Hazards } \\
\hline New Entrants & Low barriers for foreign consultancy firms, small size engineering firms. etc. \\
\hline Substitutes & In-house engineering services, Freelance service providers \\
\hline Suppliers & Oversupply of unskilled engineering graduates, Lack of interdisciplinary, Social culture \\
\hline Customer & Preference of low cost than value, Vagueness requirements \\
\hline Stakeholders & "Changes" of regulations or currency value, delays of approval and permission process \\
\hline \multicolumn{2}{|l|}{ Internal Hazards } \\
\hline $\begin{array}{l}\text { Strategicand } \\
\text { Management }\end{array}$ & $\begin{array}{l}\text { Unclear objectives and policies, Inefficient leadership, Deficiencies in organization procedures, } \\
\text { Absence of training or common culture }\end{array}$ \\
\hline Human factor & Unprofessional human traits \\
\hline Assets & Work area and infrastructure, Insufficient material, equipment failure, Poor information system \\
\hline Environment & Miscommunication, disintegration between activities, Lack of synergy between working team \\
\hline Processes & $\begin{array}{l}\text { Inefficient, misunderstanding of process requirements, Poor management of changes, Shortage of } \\
\text { knowledge transfer }\end{array}$ \\
\hline
\end{tabular}

\subsection{Evaluating Risks}

The evaluation of identified risks, which results from the interaction between hazards and system's components, is based on four point scale either for the estimating probability of occurrence of an undesirable event or for

\begin{tabular}{|c|c|c|c|c|c|c|c|c|}
\hline \multicolumn{4}{|c|}{ Table 2: Four point Risk Scale } & & \multicolumn{4}{|c|}{ Frequency $(\mathrm{F})$} \\
\hline G & $\mathrm{Y}$ & $\mathrm{O}$ & $\mathrm{R}$ & & 1 & 2 & 3 & 4 \\
\hline \multirow{5}{*}{$\begin{array}{l}\text { Acceptable } \\
\text { No action to } \\
\text { be taken }\end{array}$} & \multirow{5}{*}{$\begin{array}{l}\text { Tolerable } \\
\text { Monitoring } \\
\text { measures } \\
\text { are } \\
\text { required }\end{array}$} & \multicolumn{2}{|c|}{ Inadmissible Refused } & 4 & R4 & R4 & R4 & $\mathrm{R} 4$ \\
\hline & & \multirow{4}{*}{$\begin{array}{l}\text { g Control } \\
\text { measures a } \\
\text { needed } \\
\text { mitigation }\end{array}$} & \multirow{3}{*}{$\begin{array}{l}\text { Control } \\
\text { remeasures of } \\
\text { reducing }\end{array}$} & 3 & $\mathrm{O} 3$ & $\mathrm{O} 3$ & $\mathrm{R} 4$ & $\mathrm{R} 4$ \\
\hline & & & & 2 & $\mathrm{Y} 2$ & $\mathrm{Y} 2$ & $\mathrm{O} 3$ & $\mathrm{R} 4$ \\
\hline & & & & \begin{tabular}{|l} 
\\
in 1
\end{tabular} & GI & G1 & $\mathrm{Y} 2$ & $\mathrm{O} 3$ \\
\hline & & & $\begin{array}{l}\text { risk should } \\
\text { be taken }\end{array}$ & \multicolumn{5}{|c|}{ Fig. 3. The risk matrix } \\
\hline
\end{tabular}

evaluating the severity of its consequences. These two factors, probability and severity form a risk matrix used to measure the criticality of the event, Fig 3 . The values of probability and severity are estimated from the historical data and expert judgmentof the pilot case. The matrix resulted in four ranks of risks, Table 2; the two ranks (G1\&Y2) are acceptable risks and the other ranks (O3\&R4) for unacceptable risks.

\section{Results Obtained from the Case Study}

Results obtained from the study of the pilot project, show that most of the risk scenarios are tolerable, third category, but need monitoring measures to prevent them from escalating to higher categories of risks. The percentage of unacceptable risk scenarios is $24 \%$ of the total risk, where 3\% are totally refused risks, Fig. 4 . This is expected for a service based industry; particularly the majority of firm's activities are highly depending on the ordinary office work.Accordingly, in this case study, the recommended control measures vary between improving the work procedures in the organization to fulfil the requirements of system complexity, and developing a clear training plan based on the actual needs of the 
organization. As the observed risk scenarios in the system are generated from the interaction between functional units and the potential hazard, the analysis showed that the external hazards which confronts the system represents $17 \%$ of the total hazards confronts the company of the study. The analysis handled 418 risk scenarios that have different potential of occurrence and severity Table 3. Further investigation for the scenarios is carried out with emphasis on the results of functional analysis of the case company. Observation shows that the highest number of risks is generated in the "Project Management" process, which is a key process in engineering consultancy industry, while the least number of risks included in the process of "Business Development," which is the starting process for the business. Obviously these results indicate that, although getting an opportunity is important for the business and solving customer's problem is essential, but doing these jobs successfully by effective project management process guarantees the continuity of the work.

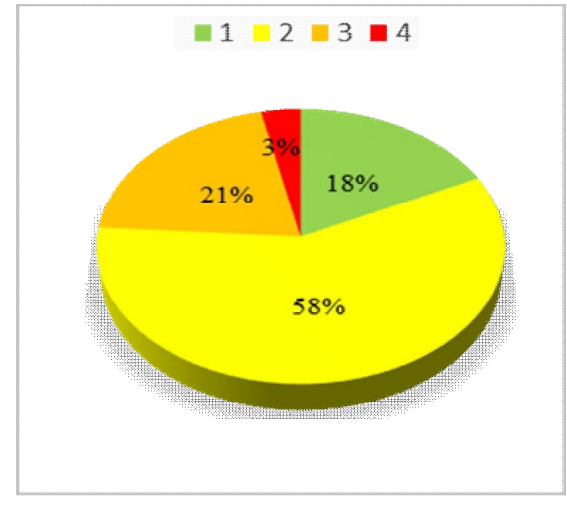

Fig. 4: Distribution of Risks in the Case

Table 3. Distribution of Risk Scenarios in the Pilot Project

\begin{tabular}{|l|c|c|c|c|c|}
\hline Work Phase & C1 & C2 & C3 & C4 & Total \\
\hline Business Development & 13 & 29 & 13 & 2 & 57 \\
\hline Project Management & 27 & 109 & 43 & 6 & 185 \\
\hline Core work processes & 19 & 62 & 18 & 1 & 100 \\
\hline Supportive work processes & 15 & 44 & 12 & 5 & 76 \\
\hline Total & 74 & 244 & 86 & 14 & 418 \\
\hline
\end{tabular}

For better visualization, the unacceptable risks are plotted on radar graph, Fig. 5. Results shows that project management work processes is the weakest point with respect to the inadmissible risks. While we move to the fourth category, where the most critical risks are located, the proportions of the risk scenarios which related to core and supportive work processes are convergent, which reveals the importance of including supportive work processes during studying the system, even though they do not have direct input to technical issues of engineering business.

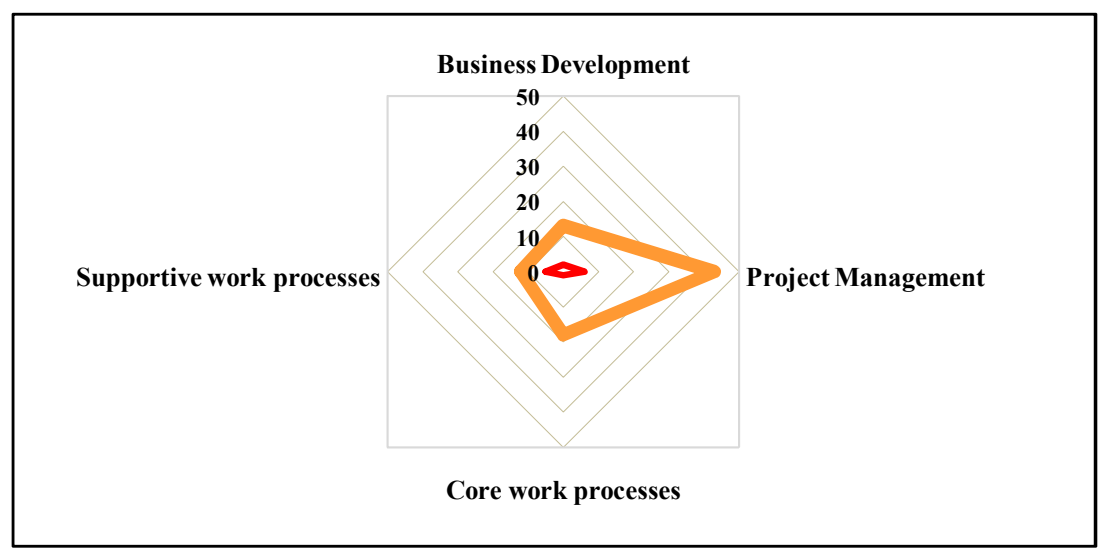

Fig. 5 Distribution of unacceptable risks per work process

\section{Conclusions}

This research is an initiation to promote interdisciplinary studies by proposing risk management as a tool to scrutinize/analyse and improve management system in the engineering consultancy industry. The research used a systemic approach for risk management by adopting a French model (APR) on one of the Egyptian engineering expert houses. The research reveals that the intolerable risks may exists in non- technical issues, however it has a significant negative impact on the performance of the whole system. Therefore a systemic study of all the system components, 
operations, and structure is a fundamental prerequisite before handing the process of risk management, particularly because of the independence of the performance of any system (and consequently the continuity of business) on the influence of its sub-systems. It is recommended to perform further researches on other sectors of engineering services based on a holistic approach which covers both technical and other issues, such as the environment and social aspects in the system.

\section{References}

1. Araoz, Alberto. Consulting and engineering design in developing countries. IDRC, Ottawa, ON, CA, (1980).

2. Stroe, G. S. Management \& Marketing 8, no. 1 (2013).

3. Rimmer, P. J. In Services and metropolitan development, pp. 90-130. Routledge, (2002).

4. Chapman, C., \& Ward, S. How to manage project opportunity and risk: Why uncertainty management can be a much better approach than risk management. John Wiley \& Sons, (2011).

5. Lehtiranta, L. Inter. Jour. of Project Manag. 32, no. 4 (2014): 640-653.

6. Garvey, P. R. Analytical methods for risk management: A systems engineering perspective. Chapman and Hall/CRC, (2008).

7. Goral, J. Risk management in the conceptual design phase of building projects. (2007).

8. Dym, C. L., Agogino, A. M., Eris, O., Frey, D. D., \& Leifer, L. J. Jour. of eng. education, 94(1), 103-120, (2005).

9. Egyptian Syndicate of Engineers. http://eea.org.eg/PageDetails.aspx?ID=276. Engineering Regulations. [Online] September 15, 2018.

10. Desroches, A., Baudrin, D., \& Dadoun, M.: L'analyse préliminaire des risques: principes et pratiques. Hermes science publications, (2009).

11. Martino, R. E. A. System architecture of a consulting engineering services firm and its application to information system development. (Doctoral dissertation, Massachusetts Institute of Technology), (2007).

12. Delmotte, S., Desroches, A. L'analyse globale des risques quantitative. 19th Congres de maitrise des risques et sureté de fonctionnement - Dijon 21-23 octobre 2014.

13. Porter, M. E. The five competitive forces that shape strategy; Harvard business review, 86(1), 78-93, (2008).

14. Cooke-Davies, T. J., \& Arzymanow, A. The maturity of project management in different industries: An investigation into variations between project management models. Inter. Jour. of Project Management 21, no. 6: 471478, (2003). 